\title{
Clinical Management of Complete Uterine Eversion in a Jersey Crossbred Cow
}

\author{
D.K. Sarma*, P.M. Barua, A. Haque and Nipjyoti Nath \\ Department of Animal Reproduction, Gynaecology and Obstetrics, College of Veterinary \\ Science, Assam Agricultural University, Khanapara, Guwahati-781022, Assam, India \\ *Corresponding author
}

\section{A B S T R A C T}

Keywords

Cow postpartum uterine prolapse reposition.

Article Info

Accepted:

17 September 2017

Available Online:

10 November 2017
A jersey crossbred primipara cow was reported to have complete uterine prolapse 3 hours after delivery of a large sized male calf. Correction operation was started with Lignocain- Xylazine combined epidural anaesthesia@8ml and $0.3 \mathrm{ml}$, respectively. Then the prolapsed mass was placed inside after cleaning properly with potash solution, reducing the oedema with sugar application and preventing the haemorrhages. Shoe lace suture was applied for prevention of reoccurrence. Ceftiofur was administered IM @2.2mg/kg bwt/day for 5 days along with other supportive therapy. The cow recovered without any complications.

\section{Introduction}

The prolapse of uterus may be very severe if the mass protrudes completely outside the body for prolong and receives lacerated injury. The oedema, infection and haemorrhages developed thereby make the correction of the condition challenging for veterinarian. The complete uterine prolapse is most common at or immediately after calving. The weakening of perivulvar muscles and mesometrium, retention of placenta, milk fever, excessive relaxation of pelvic and perineal region, dystocia, sloppy floor, etc may be attributed to the causes of the uterine prolapse (Roberts, 1971). Though complete uterine prolapse is considered as life threatening complication of parturition but rapid and effective treatment can ensure the survival, recovery and even fertility of the affected animal. The present communication placed on record a case of postpartum complete uterine eversion in a crossbred jersey cow in its first parturition.

\section{Case history and clinical observations}

One Jersey crossbred cow, weighing about $270 \mathrm{~kg}$, at her first parturition was being reported to have a problem of appearance of a reddish fleshy mass through the vulva at about 3 hours after parturition of a healthy male calf. The owner stated that the cow was struggling for 3-4 hours during her second stage of labour but failed to deliver it of her own. Lastly, forced extraction was done with 
three men's force application. Immediately after calving she started straining severely and about 3 hours later a big muscular structure was protruded out. On examination, the uterus was found to be everted out completely (Figure 1). There were profuse haemorrhages and whole of the mass was stained with blood and became highly oedematous. The placenta was found to be partly adhered on the caruncles. The cow was dehydrated and rectal temperature was $101^{0} \mathrm{~F}$.

\section{Treatment and Discussion}

The restraining of hind quarter of the cow was achieved with the application of epidural anaesthesia (combination of $8 \mathrm{ml} 2 \%$ Lignocaine Hydrochloride and $0.3 \mathrm{ml}$

Fig.1 Part of the prolapsed uterus

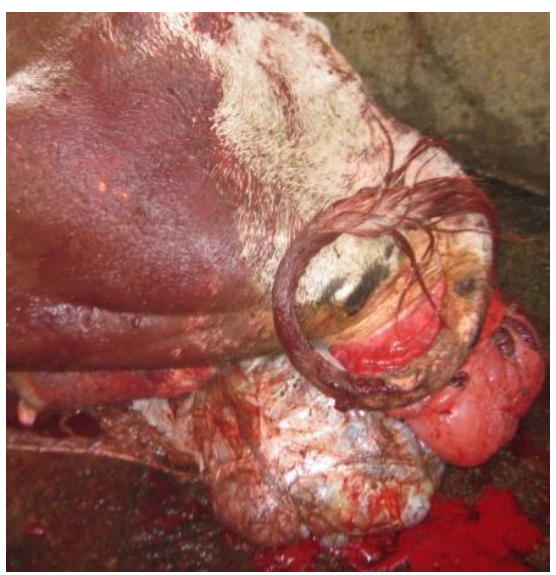

xylazine) injected into sacro-coccygeal space. The soiled and contaminated prolapsed uterus was cleaned thoroughly with light Potassium permanganate solution. The loosely attached placenta was carefully removed from the caruncles and haemorrhagic points were ligated with 2.0 sized chromic catgut. The super saturated sugar solution was used over the prolapsed uterus for reduction of oedema. Antiseptic ointment (Povidone iodine) was applied thoroughly over the uterus. Keeping the cow on sterna recumbency the prolapsed organ was lifted up to the level of vulva.

Then the organ was pushed gently inside using palm and hand fist and finally placed in-situ following the procedure described by Plenderleith (1980) (Figure 2).

Fig.2 Reposition of prolapsed uterus

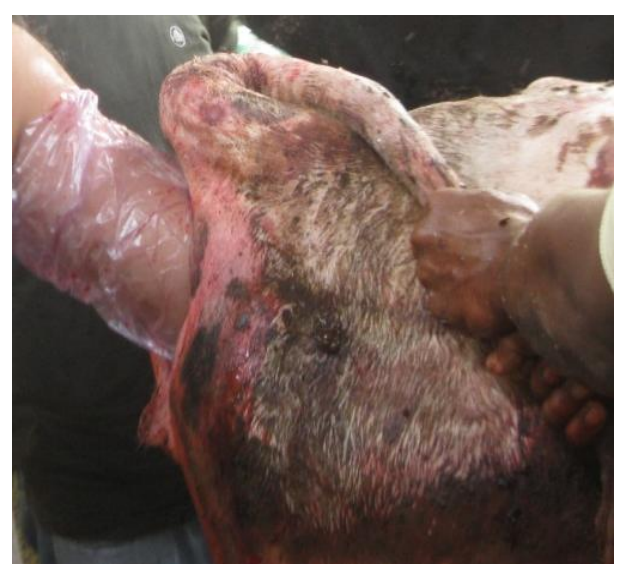

Fig.3 Closure of vulva with shoelace technique

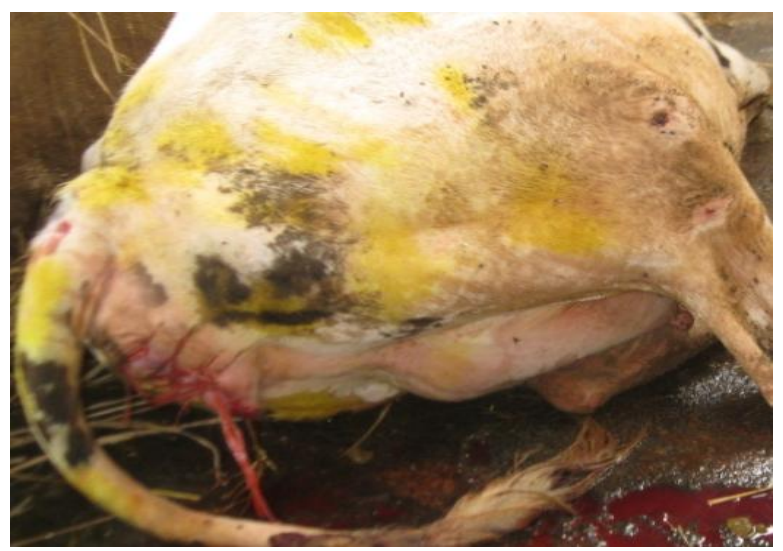


Finally, the retention of reverted and placed organ was maintained with the help of shoelace suture technique with nonabsorbable plastic materials (Figure 3). A course of antibiotic (Ceftiofur @ $2.2 \mathrm{mg} / \mathrm{kg}$ body weight) was continued daily for 5days. $25 \%$ dextrose with electrolyte solution was infused (4 litres to combat the dehydration). Anti-histamine was (15ml i.m.) given before infusion of $250 \mathrm{ml}$ of Calcium borogluconate. Methyl Ergometrine Maleate (5 ml i.m.) was injected after reposition of the organ for early involution of the uterus and to control haemorrhage. The cow was gradually returning towards normal without any straining and pus discharge from the vulva and subsequently sutures were removed and was found to be recovered completely. The prolapsed uterus is highly susceptible to trauma, laceration, haemorrhages, necrosis and infection leading to higher morbidity of the affected cow (Jana and Ghose, 2004), if not treated earlier. The present case of complete uterine eversion was suspected to have occurred following development of uterine inertia due to prolonged second stage of parturition during delivery of a heavy male calf by a heifer at her first calving. Arthur et al., (1996) also stated the uterine inertia as an exciting factor for eversion of uterus. Though the incidences of complete uterine prolapse is said to be more frequent in beef breed heifer than the dairy breed heifers (Murphy and Dobson, 2002) but the present case was observed in a jersey heifer at her first lactation which could be corrected without any complications and fatality.

\section{References}

Arthur, G.H., Noakes, D.K. and pearson, H. (1996). In Veterinary Reproduction and Obstetrics (Theriogenology), $6^{\text {th }}$ edn. Bailliere and Tindal, London, P- 38489.

Jana, D. and Ghosh, M. (2004). Management of prepartum cervical prolapse in an indigenous she buffaloe. $-\mathrm{A}$ case report,Intas Polivet, 5: 147-48.

Murphy, A.M. and Dobson, H. (2002). Prediposition, subsequent fertility, and mortality of cows with uterine prolapsed. Vet. Rec. 151:733-35.

Plenderleith, R.W. (1980). Proc. Brit. Cattle Vet. Assoc. (1980-81), 55. Cited in Arthur's Veterinary Reproduction and Obstetrics, $8^{\text {th }}$ Edn. edt. By Noakes, D.E., Parkinson, T.J. and England, G.C.W. Published by W.B. Saunders Co.Philadelphia, P-335

Roberts, S. J. (1971). Veterinary obstetrics and genital Diseases (Theriogenology), $2^{\text {nd }}$ edn. CBS Publishers and Distributers, India. PP: 308.

\section{How to cite this article:}

Sarma, D.K., P.M. Barua, A. Haque and Nipjyoti Nath. 2017. Clinical Management of Complete Uterine Eversion in a Jersey Crossbred Cow. Int.J.Curr.Microbiol.App.Sci. 6(11): 2196-2198. doi: https://doi.org/10.20546/ijcmas.2017.611.259 